\title{
The Prevalence of Hypodontia and Hyperdontia in Orthodontic Patients
}

\author{
Vildana Dzemidzic ${ }^{1}$, Enita Nakas ${ }^{1}$, Irena Gagula ${ }^{2}$, Jasmina Kozadra ${ }^{1}$, Alisa Tiro ${ }^{1}$ \\ ${ }^{1}$ Department of Orthodontics, School of Dental Medicine, University of Sarajevo, Bosnia and Herzegovina, ${ }^{2}$ Dental \\ Department, The Health Centre of Sarajevo Canton, Sarajevo, Bosnia and Herzegovina
}

Correspondence: vdzemidzic@hotmail.com; Tel.: + 38733214 249; Fax.: +387 33443395

Received: 2 October 2019; Accepted: 6 February 2020

\begin{abstract}
Objective. The aim of this study was to assess the prevalence of hypodontia and hyperdontia among a group of orthodontic patients. Materials and Methods. This cross sectional study was conducted using radiographs of 4256 patients (2032 males and 2224 females) who attended the Department of Orthodontics, School of Dental Medicine, University of Sarajevo. Radiographs were examined for the prevalence of hypodontia and hyperdontia in permanent dentition. Hypodontia was recorded when a tooth was absent on the panoramic radiograph and hyperdontia was recorded as an increased number of teeth above that described by normal dental formula. All data were analyzed using descriptive statistics including frequency and percentage, and differences between groups were tested using the $\chi 2$ test, or Fisher exact test. Results. In the sample of orthodontic patients, $4.08 \%$ subjects had a least one dental anomaly, hypodontia or hyperdontia. The observed prevalence of hypodontia was in $3.42 \%$ subjects, and it was more prevalent in females than in male subjects. The observed prevalence of hyperdontia was in $0.65 \%$ subjects and hyperdontia was more common in males than female subjects. Conclusions - By early diagnosis of a reduced or increased number of teeth, various modes of therapy with a multidisciplinary approach may be performed to correct the aesthetic and functional problems caused by hypodontia or hyperdontia.
\end{abstract}

Key Words: Prevalence • Hypodontia • Hyperdontia • Orthodontic.

\section{Introduction}

Dental anomalies are often encountered in orthodontic patients. They occur either in isolation or as a part of certain syndromes. Anomalies include irregularities in the number, size, shape, structure and position of the teeth. Factors leading to dental developmental disorders can be either congenital, such as inheritance, metabolic and gene mutations; or environmental factors that include physical, chemical and biological factors. In addition, some of these anomalies are caused by a combination of genetic and environmental factors (1). Disorders occurring in the initial stage of tooth development are manifested in a reduced or increased number of teeth (2).

There are several forms of reduced numbers of teeth: anodontia representing congenital absence of all teeth, oligodontia is the congenital absence of six or more teeth and hypodontia represents the congenital absence of less than six teeth. The prevalence of hypodontia has been investigated in different communities and ethnic groups, and the results are presented in several studies (3-8). The reported hypodontia rates range from $3.48 \%$ in a Spanish population, to $9.4 \%$ in a Japanese population. The wide range of the prevalence of hypodontia is a result of racial differences, sample size and different diagnostic criteria.

The most commonly affected tooth agenesis is the second mandibular premolar, followed by the maxillary lateral incisor and the second maxillary premolar; while unilateral occurrence of tooth agenesis is more common than bilateral (2). Gender differences in the prevalence of hypodontia have also been observed, where females were more affected compared to males (9). 
Hyperdontia, or supernumerary teeth, is defined as an increased number of teeth, meaning more than 20 deciduous teeth and more than 32 teeth in permanent dentition. Hyperdontia is more common in permanent dentition, and the prevalence of hyperdontia is between $0.3 \%$ and $3.8 \%$ in permanent dentition, while their occurrence in deciduous dentition ranges from $0.3 \%$ to $0.8 \%$ (4, 10-12). The etiology of hyperdontia still remains unclear. There are several theories that explain its occurrence, but heredity affects the appearance of hyperdontia (13).

The occurrence of supernumerary teeth may be single or multiple, unilateral or bilateral, or they may be impacted or erupted. Males are more often affected than females - approximately twice as often (14). Supernumerary teeth can be classified according to morphology as conical, tuberculate, supplemental and odontoma, and their localization as mesiodens, paramolar and distomolar (13). Several syndromes and disorders are associated with the occurrence of single or multiple supernumerary teeth, such as Gardner's syndrome, Cleidocranial dysplasia, and cleft lip and/or palate, and the occurrence of multiple supernumerary teeth without a syndrome is a rare phenomenon $(13,15)$.

The aim of this study was to assess the prevalence of hypodontia and hyperdontia among a group of orthodontic patients.

\section{Materials and Methods}

The study was undertaken using the panoramic radiographs of 4256 orthodontic patients (2032 males and 2224 females), from the files of the Department of Orthodontics, School of Dental Medicine, University of Sarajevo, from January 2015 to December 2017. The study included all patients who needed orthodontic treatment, and whose diagnostic protocol included radiographs, which were analyzed for the purposes of this study. Patients aged from nine to sixteen years were included to take into account the onset of mineralization of all teeth, except the third molars. All patients included in this study were natives of Bosnia and Herzegovina. All patients with syndromes or general development disorders and patients who were undergoing or had previously received orthodontic treatment were excluded from the study.

Hypodontia was recorded when a tooth was absent on the panoramic radiograph, excluding a history of loss due to trauma, caries, periodontal disease or orthodontic extraction. All permanent teeth were investigated, excluding third molars. On the basis of medical history the possibility of tooth agenesis due to extraction was excluded. Hyperdontia was recorded as an increased number of teeth above that described by normal dental formula. The overall prevalence was studied of hypodontia and hyperdontia, as well as the pattern of their occurrence regarding the affected side (left vs. right), jaw (maxilla vs. mandible), tooth type, tooth number and gender. All analysis of panoramic radiographs was carried out by one orthodontics specialist.

\section{Statistical Analysis}

Data were analyzed using descriptive statistics, including frequency and percentage. The differences between groups were tested using $X^{2}$ statistics, or Fisher exact tests. The level of significance was set at $p<0.05$. The Statistical Package for Social Sciences (SPSS, version 20.0) was used for data analysis.

\section{Results}

In the sample of 4256 digital panoramic radiographs of orthodontic patients, there were 2032 (47.75\%) males and 2224 (52.25\%) females. From the total of selected and analyzed radiographs, 174 (4.08\%) had a least one dental anomaly: hypodontia or hyperdontia. Hypodontia was found in 146 (3.42\%) subjects, out of which $64(1.50 \%)$ were males and $82(1.92 \%)$ female subjects. There was no significant difference between the genders $\left(x^{2}=0.87 ; \mathrm{P}>0.05\right)$ (Figure 1.). Hyperdontia was found in $28(0.65 \%)$ subjects, of which $18(0.42 \%)$ were male and $10(0.23 \%)$ female subjects, and there was no statistically significant difference between them $\left(\mathrm{x}^{2}=0.71 ; \mathrm{P}>0.05\right)$ (Figure 1). 


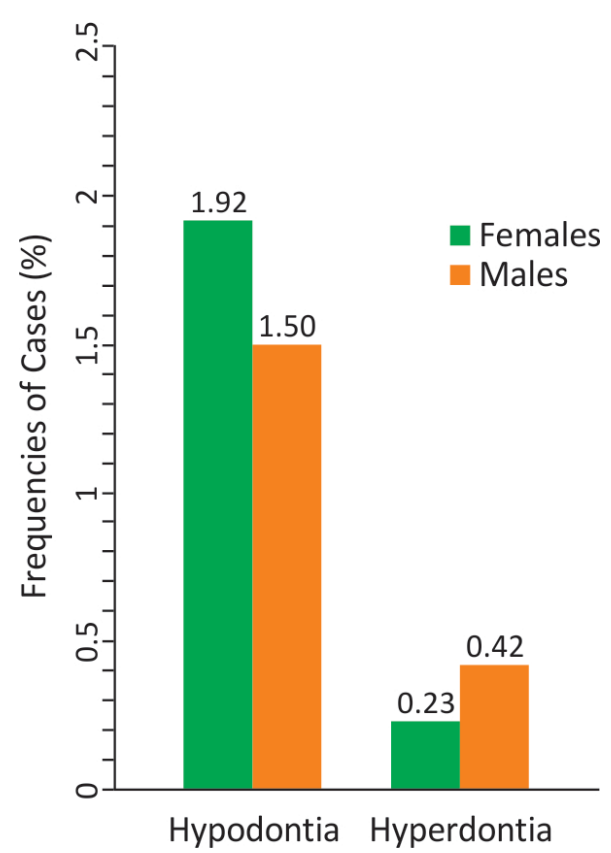

Figure 1. Frequencies of hypodontia and hyperdontia according to gender.

Figure 2 shows the data on the presence of tooth agenesis in relation to jaws. 61 (1.42\%) subjects had agenesis in the upper jaw $(0.72 \%$ males and $0.70 \%$ females), $67(1.57 \%)$ in the lower jaw (0.68\% males and $0.89 \%$ females) and $18(0.39 \%)$ in both jaws $(0.09 \%$ males and $0.30 \%$ females $)$. The appearance of tooth agenesis in the upper or lower jaw had no statistically significant value ( $P>$ $0.05)$. Unilateral agenesis of teeth was found in 37 $(0.86 \%)$ male and $33(0.77 \%)$ female subjects, and $27(0.63 \%)$ male and $49(1.15 \%)$ female subjects had bilateral agenesis; but the difference was not statistically significant $\left(x^{2}=0.47 ; \mathrm{P}>0.05\right)$.

Figure 3 shows that the teeth most affected by agenesis were the lower second premolars, followed by the upper lateral incisors, upper second premolars and lower central incisors.

A total of seventeen $(0.39 \%)$ subjects $(0.28 \%$ males and $0.11 \%$ females) had supernumerary teeth in the upper jaw, $9(0.20 \%)$ in the lower jaw $(0.11 \%$ males and $0.09 \%$ females $)$ and only two $(0.04 \%)$ subjects $(0.02 \%$ males and $0.02 \%$ females $)$ had supernumerary teeth in both jaws. The appearance of supernumerary teeth in the upper

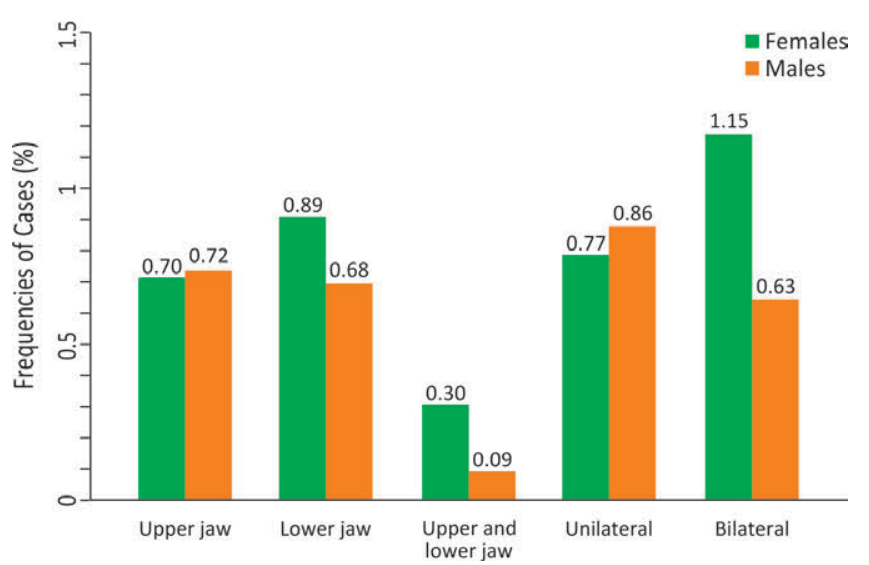

Figure 2. Frequency of hypodontia according to jaws, affected sides and gender.

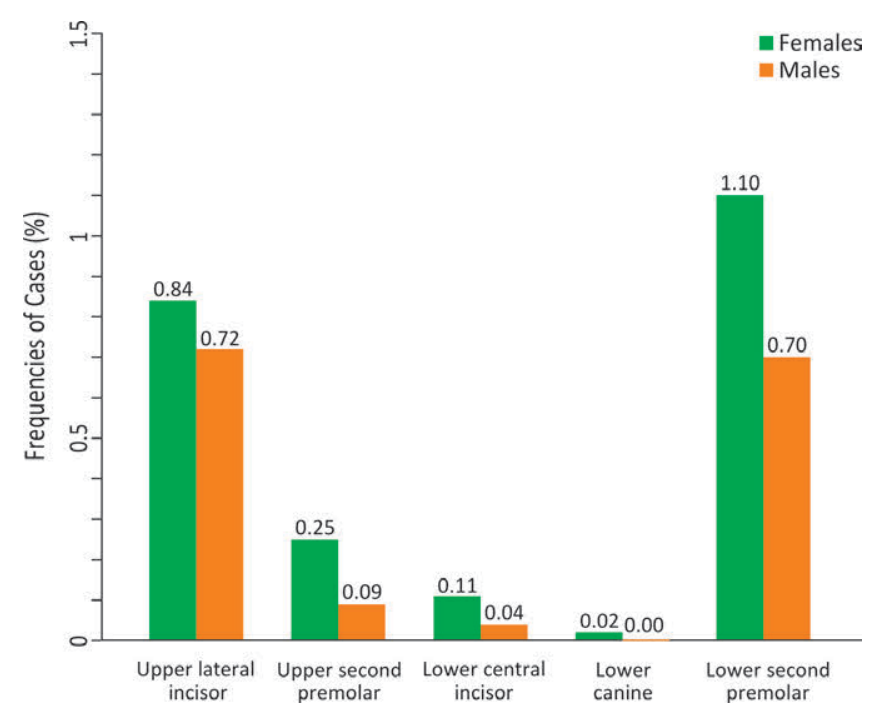

Figure 3. Frequency of hypodontia according to type of tooth agenesis and gender.

or lower jaw had no statistically significant value $(\mathrm{P}>0.05)$. These results are presented in Figure 4. Of the total number of subjects, $15(0.35 \%)$ male and $7(0.16 \%)$ female subjects had unilateral supernumerary teeth; and $3(0.07 \%)$ male and 3 $(0.07 \%)$ female had bilateral, but the difference was not statistically significant $\left(x^{2}=0.21 ; \mathrm{P}>0.05\right)$ (Figure 4).

Figure 5 shows the number and type of supernumerary teeth occurring in male and female subjects. Among the male subjects, the most common type of supernumerary tooth was mesiodens $(0.25 \%)$, followed by the lower premolars $(0.07 \%)$, 


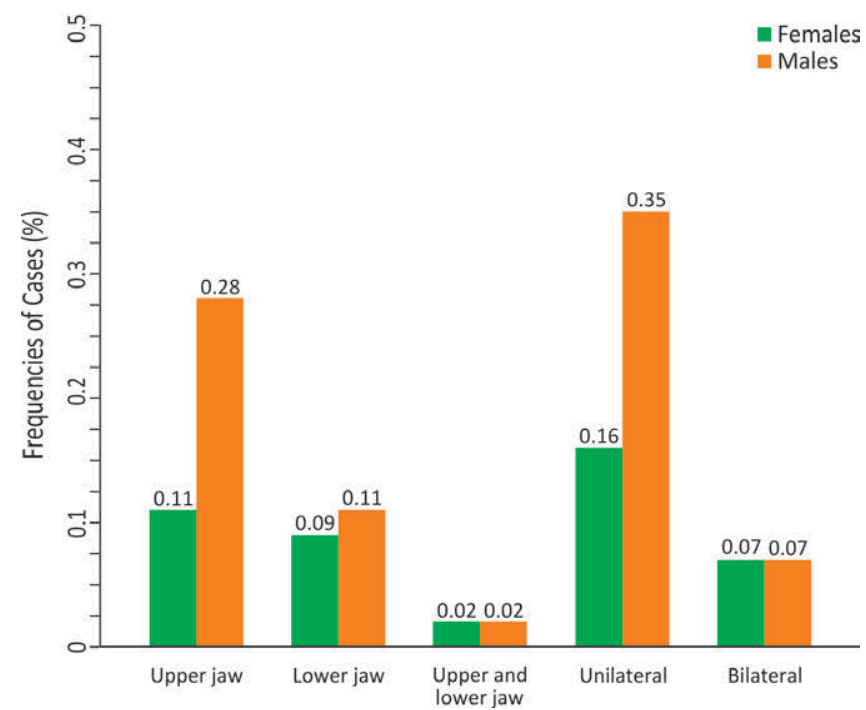

Figure 4. Frequency of hyperdontia according to jaws, affected sides and gender.

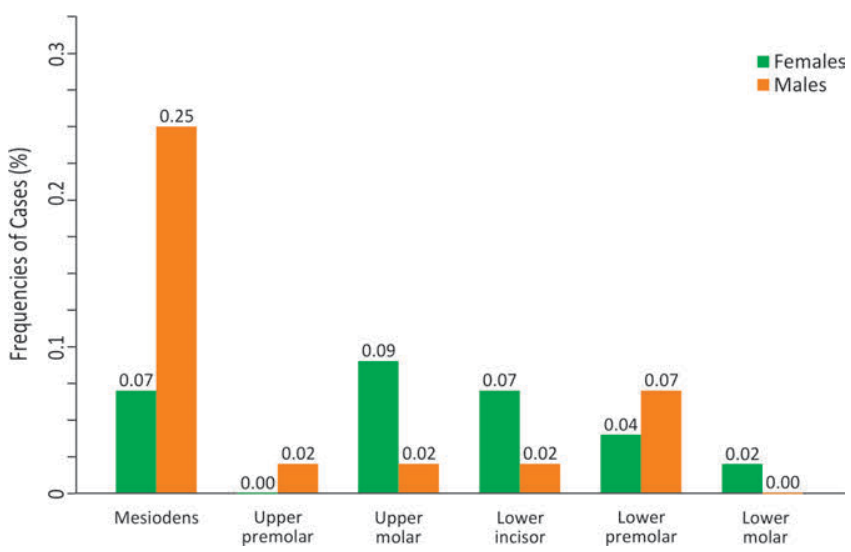

Figure 5. Frequency of hyperdontia according to type of supernumerary teeth and gender.

and the upper premolars and molars and the lower incisors were the least represented $(0.02 \%)$. The most frequent supernumerary teeth in female subjects were upper molars $(0.09 \%)$, mesiodens and lower incisors $(0.07 \%)$, followed by lower premolars $(0.04 \%)$ and molars (0.02\%).

\section{Discussion}

The reported prevalence of hypodontia, excluding the third molar, varies from $4.30 \%$ to $9.0 \%$ in the population of orthodontic patients $(5,7,11,16,17)$ and from $1.11 \%$ to $11.01 \%$ in the population of other dental patients $(3,4,6,8,12,18)$. The wide range of prevalence of hypodontia may be attributed to differences in sampling methods and sample size, as well as ethnic and racial differences. In this study, the presence of hypodontia was observed in $3.42 \%$ subjects among orthodontic patients, which is in accordance with previous, similar investigations. It was more prevalent in females $(1.92 \%)$ than in male (1.50\%) subjects, although this difference was not statistically significant, which is in accordance with reports from Japan, Norway, Portugal, Turkey, Iran, Croatia and Macedonia $(3-7,12,16)$. Only in a sample of Spanish children was hypodontia more common in male subjects, but also without any statistically significant difference (8).

Similar to the results of other studies, our results showed a significantly lower prevalence of hyperdontia $(0.65 \%)$ in relation to the prevalence of tooth agenesis. The prevalence of supernumerary teeth ranges from $0.3 \%$ to $3.8 \%(4,10-12)$. Hyperdontia is more common in males, but with no statistically significant difference, which is in accordance with other research $(10-12,15)$.

Numerous studies have reported that tooth agenesis is more common in the mandible than in the maxilla $(6,7,16,18)$, and these results were in agreement with our results. However, other studies have shown that the tooth agenesis was dominantly in the maxilla $(8,15,17)$. Bilateral tooth agenesis was more frequent than unilateral, where bilateral was more often present in female subjects, and unilateral in male subjects, but there were no statistically significant differences. However, the results of several studies have shown that the unilateral occurrence of tooth agenesis was more frequent than bilateral $(8,16,18)$, but these differences were small and were not statistically significant.

In this research, agenesis of the second lower premolar was most common, followed by the upper lateral incisor, upper second premolars and lower central incisors. Most other studies confirmed the same $(3,5,6,8,16-18)$, in contrast to some studies, where the upper lateral incisor was the most commonly affected tooth (11). Generally, 
agenesis of certain teeth was more prevalent in female subjects (Figure 3), which is related to the overall prevalence of tooth agenesis in our sample. These results explain the common occurrence of hypodontia in the mandible in our research.

Regarding the location of supernumerary teeth, they can be found in any region of the teeth, and the results of our research have shown that the largest number is in the maxillary arch, but there was no statistically significant difference between the upper and lower jaw, or between the genders. These results are in accordance with the results of the studies by Haugland et al. (5), Kazanci et al. (11), Karadas et al. (15), Gurbuz et al. (19) and Schmuckli et al. (20). A greater number of male subjects had unilateral occurrence of supernumerary teeth compared to female subjects, but the difference was not statistically significant; while the bilateral occurrence of supernumerary teeth was equally represented in both male and female subjects.

The results of the present study showed that the supernumerary teeth most commonly found were mesiodens $(0.32 \%)$ followed by premolars $(0.13 \%)$, molars $(0.13 \% \%)$, and lower incisors $(0.09 \%)$. Similar results were presented in several earlier studies $(5,15,19)$. By early diagnosis of a reduced or increased number of teeth, various modes of therapy, with a multidisciplinary approach, may be performed to correct the aesthetic and functional problems caused by hypodontia or hyperdontia.

\section{Conclusions}

The prevalence of hypodontia was observed in $3.42 \%$ subjects among orthodontic patients, and was more prevalent in females $(1.92 \%)$ than in male $(1.50 \%)$ subjects. The prevalence of hyperdontia was observed in $0.65 \%$ subjects, and supernumerary teeth are more common in males than in female subjects.

\footnotetext{
What Is Already Known on this Topic:

Dental anomalies, especially tooth number anomalies, cause problems in dental arches and occlusion. By early diagnosis of a reduced or increased number of teeth, various modes of therapy, with a multidisci-
}

plinary approach, may be performed to correct the aesthetic and functional problems.

\section{What this Study Adds:}

This study provides important information about the prevalence of dental tooth number anomalies among orthodontic patients from Bosnia and Herzegovina, which should establish appropriate therapy modalities and minimize the complications caused by these anomalies.

Authors' Contributions: Conception and design: VDZ, IG and JK; Acquisition, analysis and interpretation of data: VDZ, AT and IG; Drafting the article: VDZ, AT and EN; Revising it critically for important intellectual content: VDZ, AT and EN; Approved final version of the manuscript: VDZ, EN and AT.

Conflict of Interest: The authors declare that they have no conflict of interest.

\section{References}

1. Brook AH, Jernvall J, Smith RN, Hughes TE, Townsend GC. The dentition: the outcomes of morphogenesis leading to variations of tooth number, size and shape. Aust Dent J. 2014;59 Suppl 1:131-42.

2. Fauzi NH, Ardini YD, Zainuddin Z, Lestari W. A review on non-syndromic tooth agenesis associated with PAX9 mutations. Jpn Dent Sci Rev. 2018;54(1):30-6.

3. Goya HA, Tanaka S, Maeda T, Akimoto Y. An orthopantomographic study of hypodontia in permanent teeth of Japanese pediatric patients. J Oral Sci. 2008;50(2):143-50.

4. Campoy MD, González-Allo A, Moreira J, Ustrell J, Pinho T. Dental anomalies in a Portuguese population. Int Orthod. 2013;11(2):210-20.

5. Haugland L, Storesund T, Vandevska-Radunovic V. Prevalence of Dental Anomalies in Norwegian School Children. OJST. 2013;3(6):329-33.

6. Gokkaya B, Kargul B. Prevalence and Pattern of Non-Syndromic Hypodontia in a Group of Turkish Children. Acta Stomatol Croat. 2016;50(1):58-64.

7. Badrov J, Gaspar G, Tadin A, Galic T, Govorko DK, Gavic L, et al. Prevalence and Characteristics of Congenitally Missing Permanent Teeth among Orthodontic Patients in Southern Croatia. Acta Stomatol Croat. 2017;51(4):290-9.

8. Sola RA, Sola PA, Pérez JC, Sánchez IN, Renovales ID. Prevalence of Hypodontia in a Sample of Spanish Dental Patients. Acta Stomatol Croat. 2018;52(1):18-23.

9. Rakhshan V. Meta-analysis and systematic review of factors biasing the observed prevalence of congenitally missing teeth in permanent dentition excluding third molars. Prog Orthod. 2013;14:33.

10. Afify AR, Zawawi KH. The prevalence of dental anomalies in the Western region of saudi arabia. ISRN Dent. 2012;2012:837270. 
11. Kazanci F, Celikoglu M, Miloglu O, Ceylan I, Kamak H. Frequency and distribution of developmental anomalies in the permanent teeth of a Turkish orthodontic patient population. J Dent Sci. 2011;6:82-9.

12. Saberi EA, Ebrahimipour S. Evaluation of developmental dental anomalies in digital panoramic radiographs in Southeast Iranian Population. J Int Soc Prev Community Dent. 2016;6(4):291-5.

13. Dzemidzic V, Filipovic M, Tiro A, Nakas E, Salaga S. Multiple Supernumerary Teeth not Associated with Complex Syndromes: a Case Report. Acta Stomatol Croat. 2009;43(3):248-55.

14. Çolak H, Uzgur R, Tan E, Hamidi MM, Turkal M, Colak $\mathrm{T}$. Investigation of prevalence and characteristics of mesiodens in a non-syndromic 11256 dental outpatients. Eur Rev Med Pharmacol Sci. 2013;17(19):2684-9.

15. Karadas M, Celikoglu M, Akdag MS. Evaluation of tooth number anomalies in a subpopulation of the North-East of Turkey. Eur J Dent. 2014;8(3):337-41.
16. Acev DP, Gjorgova J. Prevalence of Hypodontia in the Permanent Dentition of Macedonian Population. Balk J Dent Med. 2014;18:93-8.

17. Gracco ALT, Zanatta S, Forin Valvecchi F, Bignotti D, Perri A, Baciliero F. Prevalence of dental agenesis in a sample of Italian orthodontic patients: an epidemiological study. Prog Orthod. 2017;18(1):33.

18. Soni HK, Joshi M, Desai H, Vasavada M. An orthopantomographic study of prevalence of hypodontia and hyperdontia in permanent dentition in Vadodara, Gujarat. Indian J Dent Res. 2018;29(4):529-33.

19. Gurbuz O, Ersen A, Dikmen B, Gumustas B, Gundogar M. The Prevalence and Distribution of the Dental Anomalies in the Turkish Population. J Anat Soc India. 2019;68(1):46-51.

20. Schmuckli R, Lipowsky C, Peltomäki T. Prevalence and Morphology of Supernumerary Teeth in the population of a Swiss Community. Schweiz Monatsschr Zahnmed. 2010;120(11):987-90. 